TP Periodica Polytechnica Chemical Engineering

\author{
62(2), pp. 236-244, 2018 \\ https://doi.org/10.3311/PPch.9972 \\ Creative Commons Attribution (1)
}

RESEARCH ARTICLE

\section{Evaluation of Radon Concentration in the Urban Area Foundation of Tirana, Albania}

\author{
Safet Dogjani ${ }^{1}$, Ylber Muceku ${ }^{1 *}$, Pranvera Lazo ${ }^{2}$
}

Received 03 September 2016; accepted after revision 19 January 2017

\begin{abstract}
In this paper, we are treating the results of radon concentration in soil gas, which are obtained by a detailed study carried out during 2000-2005 years in the urban area of Tirana, Capital City of Albania. The field measurements were done by using Luk-4 equipment (Lucas method) and based on technique [12, 18-20, 21-24]. Based on the analysis of the data taken by this research, was concluded that the level of the radon concentration in soil gas of Tirana urban area depends on the soil type. The highest level of radon gas (130.0 $\left.\mathrm{kBqm}^{-3}\right)$ was observed in inorganic clays and very fine sands with beige-red color (soils type 1), which is extended on the second terrace of Tirana River. This paper gives conclusions of soil gas radon concentration, where its value ranges from $0.9-1.54 \mathrm{kBqm}^{-3}$ up to 92.03-130.0 $\mathrm{kBqm}^{-3}$. The results indicate that more than $50 \%$ of Tirana urban area is made of soils, which are characterized by high soil radon gas concentration, which constitutes a real risk for the Tirana's residents.
\end{abstract}

\section{Keywords}

soil gas, radon concentration, measurements, high risk

\footnotetext{
${ }^{1}$ Department of Geology,

Institute of Geosciences, Energy, Water and Environment,

Polytechnic University of Tirana

str. Don Bosko, nr.60, Tirana, Albania

${ }^{2}$ Department of Chemistry,

Faculty of Natural Sciences,

University of Tirana, Tirana, Albania

"Corresponding author, e-mail: y.muceku@geo.edu.al
}

\section{Introduction}

Several publications [2-5, 8, 10-11, 27, 29-31], point out that radon gas is a real risk for human health. The presence of radon gas in soil mainly originates from the geology, and chemical composition of soils and rocks $[1,23]$. The radon level in soil and rocks range in different values. It exceeds $500 \mathrm{kBqm}^{-3}$ in regions that are built of Paleozoic granites rocks [9], in terra rossa it ranges from $100 \mathrm{kBq} \mathrm{m}^{-3}$ to $370 \mathrm{kBq} \mathrm{m}^{-3}$ [30], and in carstic environment it ranges from 25 to $420 \mathrm{kBq} \mathrm{m}^{-3}$ [31] and $100-160 \mathrm{kBqm}^{-3}[7]$.

The evaluation of radon level in soils and rocks is very important according to urban planning and development, because it is directly related to human life. Hence, for the mitigation and prevention of the dangers posed by exposure of the radon gas, it is necessary to know its geographical distribution and concentration level in soils and rocks foundation along dwelling areas. A detailed study of the radon concentrations of foundation soils was carried out in urban areas of Tirana during the years 2002-2005. This study revealed that $54.0 \%$, $14.0 \%$ and $32.0 \%$ of the Tirana urban area is respectively characterized by the high, medium and low level of radon gas concentration in the foundation soils. It means that half of the Tirana urban area is built on foundation soils, which poses a high environmental risk.

\section{Methodology}

Due to the urban planning and development of the Tirana Capital City, local and international planning companies and designers have required an engineering geological map in scale 1:10000 [13-14] as well as a detailed assessment of the radon concentration in foundation soils [6]. During the years of 20002005 , in the Tirana urban area $\left(51 \mathrm{~km}^{2}\right)$, many geo-technicians' works have been done. Initially, it was worked on data collecting of the previous studies carried out in the urban area. Subsequently, was worked on the oriented profile on scale 1:10 000 , to obtain the geotechnical data of the soils and rocks. They include 180 boreholes ( $15.0 \mathrm{~m}$ to $30.0 \mathrm{~m}$ deep), 145 Pits $(4.0 \mathrm{~m}$ to $6.0 \mathrm{~m}$ deep), 175 soils and rocks samples analyzed in laboratory for determination of mechanical and physical properties, 
as well as geophysical investigations-vertical electrical soundings-VES. These works enabled the compilation of engineering geological map on scale 1:10000, of Tirana City, which provides data according to terrain morphology, soils and rocks geotechnical properties, hydrogeological conditions and mass movements characteristic etc. Also, in addition to geotechnical works during the years of 2000-2005, have been worked for the evaluation of the radon concentration in the foundation soils [6].

\subsection{Measurements of radon concentration in soil gas}

The measurements were done on flat $\left(31 \mathrm{~km}^{2}\right)$ and hill $\left(9.0 \mathrm{~km}^{2}\right)$ morphological units of the urban area. Every $\mathrm{km}^{2}$ was divided into 4 square $(0.5 \times 0.5 \mathrm{~km})$, and in each of them was chosen a testing site (preferably in its centre) with 250 $\mathrm{m}^{2}$. Fifteen measurements of ${ }^{222} \mathrm{Rn}$ are performed according to a quadratic grid in these testing sites. Additionally, 3 measurements were permeability performed in these testing sites. Based in this methodology, 2400 measurements of ${ }^{222} \mathrm{Rn}$ have been carried out in 127 and 33 squares, respectively in flat and hill morphologic unit of the Tirana urban area. There are used Luk-4 equipment (Lucas method) and based on measurements technique [7, 18-20, 22-23]. The soil gas sample were usually collected using a small diameter hollow steel probe with a free, sharpened lower end (a lost tip) combined with a large volume syringe. The soil gas samples were usually collected for radon concentration measurements at depth of $0.8 \mathrm{~m}$ below the ground surface. Measurements were performed 6 minutes after the entering of the gas in Lucas cells with the volume of $125 \mathrm{~cm}^{3}$, time required, the level of ${ }^{222} \mathrm{Rn}$ is practically equal to zero. This interval of time is necessary in order the ${ }^{222} \mathrm{Rn}$ to decay totally (half time decay of $55.0 \mathrm{sec}$ ) [12]. Each $\mathrm{km}^{2}$ was divided into 4 square $(0.5 \times 0.5 \mathrm{~km})$, and in each of them was chosen a testing site (preferably in centre) with $250 \mathrm{~m}^{2}$. In this testing site was performed 15 measurements of ${ }^{222} \mathrm{Rn}$ on a quadratic grid $(5.0 \times 5.0 \mathrm{~m})$ and 3 measurements of the permeability. Finally, were determined the ${ }^{222} \mathrm{Rn}$ and permeability results, which represent the mean values.

\section{Results}

It should be emphased that the data obtained from engineering-geological mapping on scale 1:10000, were very useful for specialists that have measured the radon concentration in soils, because there is a good relation between the soils types and radon concentration level in the studied area [17]. Therefore, in this approach we are analyzing the radon concentration level in the foundation soils of the Tirana urban area, and the geological factors that are prone of radon, as well. In this paper, we are analyzing the evaluation of ${ }^{222} \mathrm{Rn}$ concentration in the flat morphological unit of the Tirana urban area, because it constitutes the main part of it, in the present and the future.

\subsection{Characteristics of Foundation Soils}

Based on the analysis results of chemical composition and physical and mechanical properties of cohesive soil samples performed in Tirana urban area, it was concluded that geotechnical properties and major chemical elements have a range of variation in composition from one to another morphological site [16]. So, the soils we are describing in accordance with the morphological units, where they belong. From the geomorphological point of view, the studied area, where the measurements of ${ }^{222} \mathrm{Rn}$ are carried out is included in flat morphological unit [15]. It is composed of alluvial deposits that are situated on molasses rocks of Tirana syncline. The alluvial deposits build the first and second terrace of Tirana River and Lana River terrace (Fig. 1, 2).

The first terrace of Tirana River: It is extended on the northern part of Tirana urban area on both side of the Tirana River (Fig. 1). This terrace is built by (Fig. 2):

Soil type 1: It consists of sandy clays-CL [26] (1.8-3.7m thick) with low plasticity with brown color, which lie in the upper part of lithological profile. It is situated over gravel soils. Among these soils were found also soils type consisting of inorganic clays and very fine sands with beige-red color, which are prone to the high radon gas value.

Soil type 2: It is composed by the gravel-sand-clays mixtures-GC type [26], saturated, grey color, which is in medium to dense state, $3.0-5.0 \mathrm{~m}$ thick. It lies over molasses rocks.

The second terrace of Tirana River: It is located in central part of Tirana urban area, extending from east to west (Fig. 1). It represents a flat area with inclination angle $2-3^{\circ}$ toward west. Due to the high value of the radon gas contents in this terrace, we are treating it in detail. Starting from the top to down of soil profile the soils types are as follows (Fig. 2):

Soil type 1: It is composed of inorganic clays and silts with intercalation of thin sands layers and low plasticity-CL type [26], which has the medium to stiff consistency, beige-red color. These soils are situated in upper part of soil's profile and it is $1.8-3.5 \mathrm{~m}$ thick. It should be noted that these soils are prone of radon gas in high level.

Soil type 2: Consists of gravelly-sand-clay mixtures-GC type [26], grey to beige color, in medium state. It has medium water content. This layer is situated below layer nr.2 and has a thickness of 4.5-6.0m.

Soil type 3: These soils are represented by the gravel-sand mixtures-GP type [26], saturated, grey color, which is in very dense state, $7.0-12.0 \mathrm{~m}$ thick. It is situated in lower part of soil profile over molasses rocks.

The terrace of Lana River: This terrace extends in southern part of Tirana urban area, on both side of Lana River (Fig. 1), forming a flat area, which dip to west with angle $3-5^{\circ}$. In all its spreading, it is built mainly by (Fig. 2):

Soil type 1: These soils are represented by inorganic silts and clays soils with sands-CL \& ML type [26], grey color. These soils are situated in the upper part of soil's profile and 

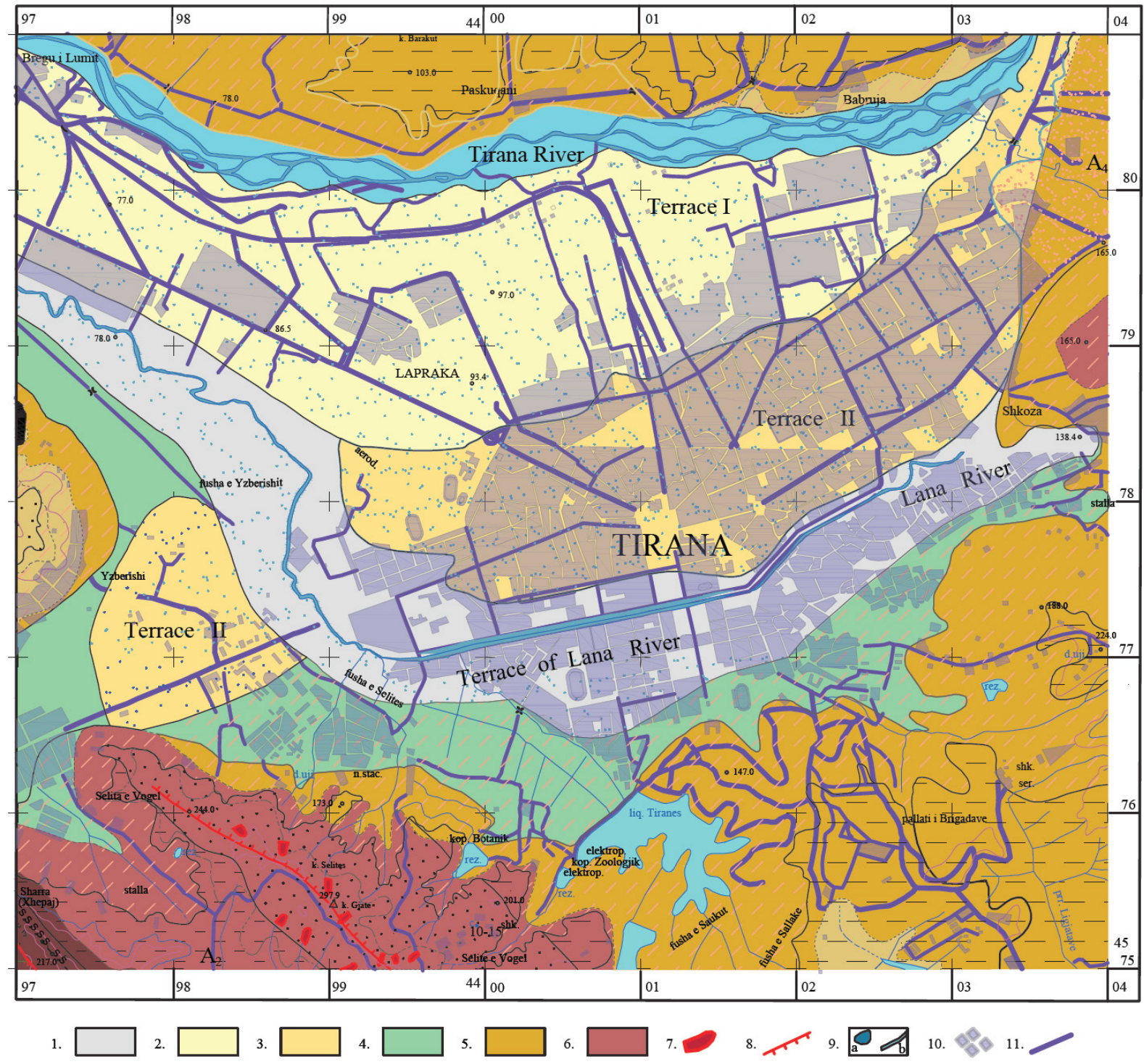

1. The terrace of Lana River: inorganic silts and clays soils with very fine sands, 2 . The first of terrace of Tirana River: sandy clays, 3. The second terrace of Tirana River: inorganic clays and very fine sands, beige-red color, 3 . The terrace of Lana River: inorganic silts and clays soils with grey colors. 4 . The hill's slope soils: inorganic clays and silts with sands, 5. soft rocks-claystone, 6. soft rocks-sandstones, 7. landslide, 8. tectonic line, 9. Lake and river, 10. Tirana City, 11. road.

Fig. 1 It shows the Morphological and Lithological Map of Tirana urban area, scale 1:10000

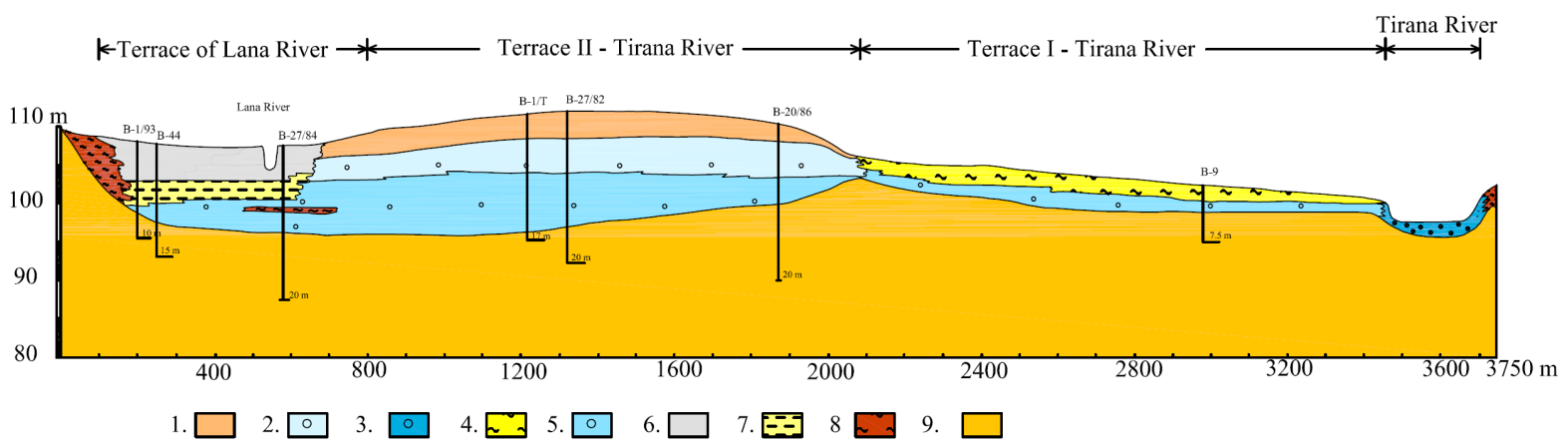

1. Inorganic clays and silts with sands, beige-red color-CL, 2. gravelly-sand-clay mixtures-GC, 3. gravel-sand mixtures-GP, 4. sandy clays-CL, 5. gravel-sandclays mixtures-GC, 6. inorganic silts and clays soils with very fine sands-CL \& ML, 7. sandy clays-CL type, 8. inorganic clays and silts with sands-ML, 9. soft rocks-claystone and sandstones

Fig. 2 It shows the lithological profile from north to south of Tirana urban area 
Table 1 Some radon's values measured in soil gas of Tirana urban area

\begin{tabular}{|c|c|c|c|c|c|}
\hline \multicolumn{2}{|c|}{ Tirana River Terrace-II } & \multicolumn{2}{|c|}{ Tirana River Terrace-I } & \multicolumn{2}{|c|}{ Lana River Terrace } \\
\hline Code no & $\begin{array}{l}\text { Unit } \\
\left(\mathrm{kBqm}^{-3}\right)\end{array}$ & Code no & $\begin{array}{l}\text { Unit } \\
\left(\mathrm{kBqm}^{-3}\right)\end{array}$ & Code no & $\begin{array}{l}\text { Unit } \\
\left(\mathrm{kBqm}^{-3}\right)\end{array}$ \\
\hline $11 \backslash 42$ & 59.0 & $1 \backslash 3$ & 0.9 & $5 \backslash 18$ & 0.9 \\
\hline $11 \backslash 43$ & 71.8 & $2 \backslash 5$ & 0.9 & $5 \backslash 20$ & 0.9 \\
\hline $11 \backslash 44$ & 70.9 & $3 \backslash 10$ & 8.7 & $6 \backslash 23$ & 15 \\
\hline $12 \backslash 45$ & 36.6 & $3 \backslash 11$ & 12.14 & $6 \backslash 24$ & 12 \\
\hline $12 \backslash 46$ & 43.4 & $3 \backslash 12$ & 13.56 & $14 \backslash 56$ & 0.9 \\
\hline $12 \backslash 48$ & 37.8 & $4 \backslash 13$ & 2.15 & $15 \backslash 57$ & 48.7 \\
\hline $16 \backslash 64$ & 92.03 & $4 \backslash 14$ & 1.54 & $15 \backslash 58$ & 0.9 \\
\hline $17 \backslash 66$ & 36.2 & $4 \backslash 15$ & 37.5 & $15 \backslash 60$ & 0.9 \\
\hline $17 \backslash 67$ & 39.4 & $4 \backslash 16$ & 3.48 & $20 \backslash 79$ & 41.2 \\
\hline $18 \backslash 69$ & 22.37 & $6 \backslash 21$ & 1.0 & $20 \backslash 80$ & 56.8 \\
\hline $18 \backslash 70$ & 78.24 & $6 \backslash 22$ & 12.78 & $21 \backslash 83$ & 11.07 \\
\hline $18 \backslash 71$ & 60.4 & $7 \backslash 26$ & 73.4 & $21 \backslash 84$ & 40.7 \\
\hline $18 \backslash 72$ & 130.0 & $7 \backslash 27$ & 47.65 & $25 \backslash 99$ & 0.9 \\
\hline $19 \backslash 73$ & 59.1 & $7 \backslash 28$ & 105.9 & $25 \backslash 100$ & 1.7 \\
\hline $19 \backslash 74$ & 56.6 & $8 \backslash 29$ & 65.55 & $27 \backslash 108$ & 74.6 \\
\hline $24 \backslash 95$ & 94.7 & $8 \backslash 30$ & 2.29 & $28 \backslash 109$ & 1.04 \\
\hline $25 \backslash 97$ & 32.9 & $8 \backslash 31$ & 95.7 & $28 \backslash 110$ & 0.9 \\
\hline $25 \backslash 98$ & 30.7 & $8 \backslash 32$ & 77.1 & $28 \backslash 111$ & 0.9 \\
\hline $26 \backslash 101$ & 40.8 & $9 \backslash 33$ & 103 & $28 \backslash 112$ & 49.4 \\
\hline $26 \backslash 103$ & 74.5 & $9 \backslash 34$ & 72.2 & $34 \backslash 133$ & 75.8 \\
\hline $26 \backslash 104$ & 43.4 & $9 \backslash 35$ & 36 & $35 \backslash 137$ & 72.1 \\
\hline $27 \backslash 105$ & 97.4 & $9 \backslash 36$ & 1.62 & $35 \backslash 138$ & 33.2 \\
\hline $27 \backslash 106$ & 83.35 & $10 \backslash 37$ & 27.9 & $35 \backslash 139$ & 84.9 \\
\hline $27 \backslash 107$ & 48.4 & $10 \backslash 38$ & 13.24 & $35 \backslash 140$ & 18.14 \\
\hline $27 \backslash 108$ & 74.6 & $10 \backslash 39$ & 15.6 & $36 \backslash 141$ & 36.9 \\
\hline $33 \backslash 131$ & 76.1 & $11 \backslash 41$ & 1.51 & $36 \backslash 142$ & 1.0 \\
\hline
\end{tabular}

they are 2.7-6.8m thick. Generally, these soils are interlayered from sandy layers. In some sites, along these soils are found the inorganic clays with beige to brown color, which are prone of radon gas in high value and has a thickness range from 2.5$5.5 \mathrm{~m}$. These soils lie over sandy clays.

Soil type 2: It is composed by sandy clays-CL type [26], grey-beige color.

Soil type 3: Consists of gravel-sand-clays mixtures-GC type [26], saturated, which is in medium to dense state, $10.0-35.0 \mathrm{~m}$ thick. It lies over molasses rocks.

\subsection{Radon concentration in soil gas}

The studied area represents the main part of Tirana urban area. From the measurements of the radon levels in soil gas, it was observed that it differs from one terrace's soils to another. So, as it is indicated in Table 1 and Fig. 3, the soils that build the second terrace of Tirana River are characterized by high radon concentration compared with the first of terrace of Tirana
River and the terrace of Lana River. The radon concentration in the foundation soils gas of the second terrace of Tirana River range from $28.0-33.6 \mathrm{kBqm}^{-3}$ up to $994.7-130.0 \mathrm{kBqm}^{-3}$.

In the foundation soil gas of the first terrace of Tirana River, was found a variation from $0.9-9.0 \mathrm{kBqm}^{-3}$ to 79.32 $105.9 \mathrm{kBqm}^{-3}$. Whereas, in the terrace of Lana River the radon concentration in foundation soil gas, ranges from 0.90 $12.0 \mathrm{kBqm}^{-3}$ to $48.7-84.9 \mathrm{kBqm}^{-3}$. By successful completion of this study, we draw very important results, which are:

I.) About $94.0 \%$ of the foundation soils of the second terrace of Tirana River are characterized by the high value $(>30$ $\mathrm{kBqm}^{-3}$ ) of the radon concentration in soil gas and $6.0 \%$ medium value $\left(10-30 \mathrm{kBqm}^{-3}\right)$. It means that these soils are categorized in high risk area $(94.0 \%)$ and medium risk area $(6.0 \%)$ of radon infiltration from the ground [21].

II.) Almost $30.0 \%$ of the foundation soils of the first terrace of Tirana River are defined as soils with high value $(>30$ $\mathrm{kBqm}^{-3}$ ) of the radon concentration in soil gas, $20.0 \%$ 

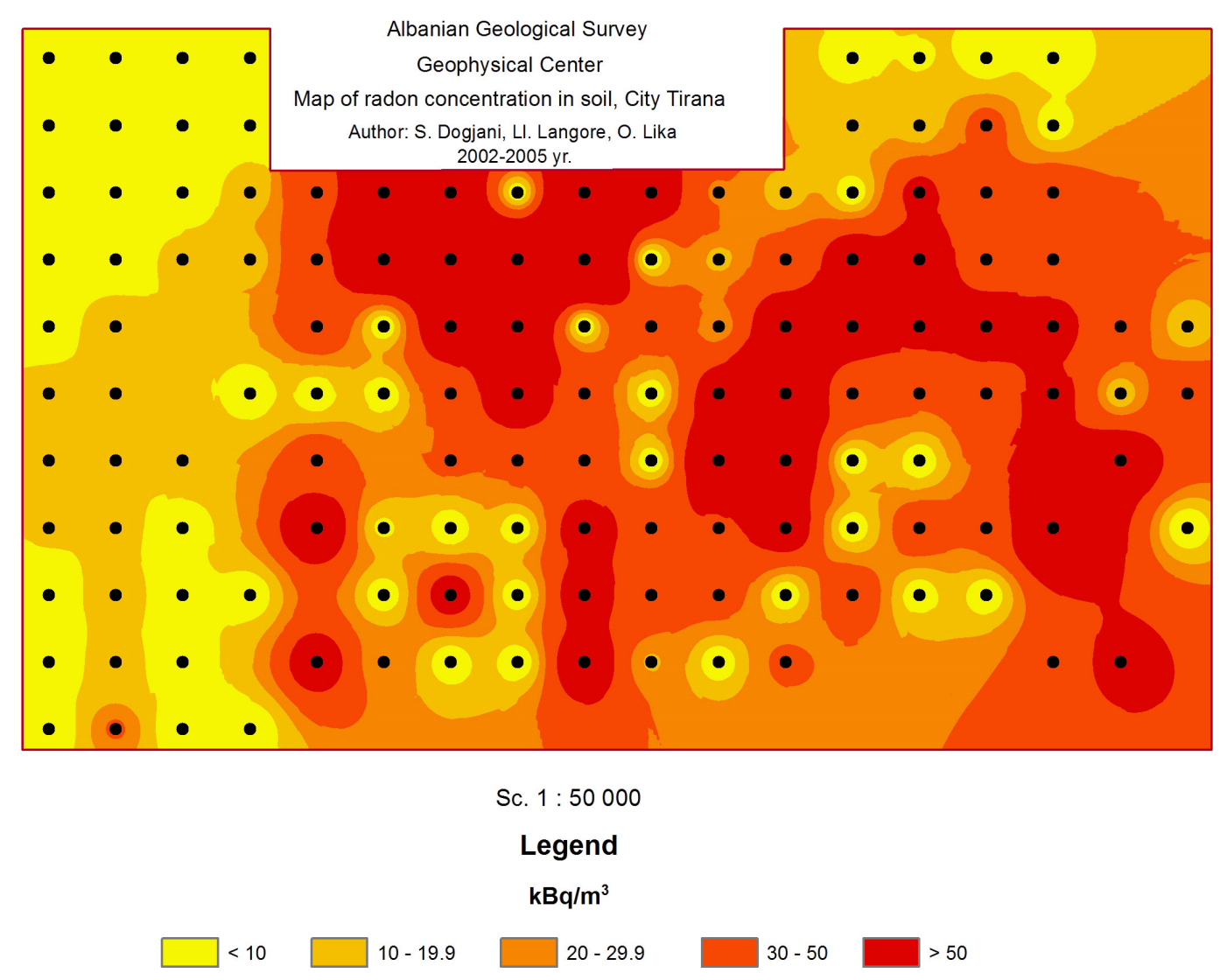

Fig. 3 It shows the geographical distribution map of the ${ }^{222} \mathrm{Rn}$ level in soils of Tirana, urban area

medium value $\left(10-30 \mathrm{kBqm}^{-3}\right)$ and $50.0 \%$ low value $\left(<10 \mathrm{kBqm}^{-3}\right)$. After [21], these soils are included in areas with high risk $(30.0 \%)$, medium risk $(20.0 \%)$ and medium risk $(50.0 \%)$ of radon infiltration from the ground.

III.) About $43.0 \%$ of the foundation soils of the terrace of Lana River are distinguished as soils with high value $\left(>30 \mathrm{Bqm}^{-3}\right)$ of the radon concentration in soil gas, $13.0 \%$ medium value $\left(10-30 \mathrm{kBqm}^{-3}\right)$ and $44.0 \%$ low value $(<10 \mathrm{k}$ $\left.\mathrm{kBqm}^{-3}\right)$. This means that the soils of this morphological unit are included in the category with high risk (43.0\%), medium risk $(13.0 \%)$ and medium risk $(44.0 \%)$ of radon infiltration from the ground [21].

IV.) Furthermore, about $54.0 \%$ of the foundation soils of the Tirana urban area are determined with high value $\left(>30 \mathrm{Bqm}^{-3}\right.$ ) of the radon concentration in soil gas, $14.0 \%$ medium value $\left(10-30 \mathrm{kBqm}^{-3}\right)$ and $32.0 \%$ low value $\left(<10 \mathrm{k} \mathrm{kBqm}^{-3}\right)$. This means that the soils of the foundation soils of the Tirana urban area are included in the category with high risk $(54.0 \%)$, medium risk $(14.0 \%)$ and low risk $(32.0 \%)$ of radon infiltration from the ground [21].

Finally, from this research was concluded that the level of the radon concentration in soil gas of Tirana urban area depends on the soils type. So, the highest level of Radon gas $\left(130.0 \mathrm{kBqm}^{-3}\right)$ was observed in the inorganic clays and silts with intercalation of thin sands layers with beige-red color (soils type 1), which is extended on second terrace of Tirana River (Fig. 1, 2, 3). These soils are situated in upper part of soil's profile and they are $1.8-3.5 \mathrm{~m}$ thick. In some places, this soil type was found in two other terraces in form of layers, which are originated from the second terrace of Tirana River as the result of erosion activities (Fig. 1, 3).

\subsection{Permeability measurements}

The measurements of permeability were performed by using of the Equipment for in-situ permeability measurements Radon-Jok. It should be noted that the measurements were carried out in a dry season (spring-summer-autumn) from May to October. It was concluded that the soil permeability $(\mathrm{k})$ of the studied area range from $10^{-11} \mathrm{~m}^{2}$ up to $10^{-13} \mathrm{~m}^{2}$.

\subsection{Data processing and statistical analyses}

The ${ }^{222} \mathrm{Rn}$ contents in soil samples were entered in a data matrix. Statistical methods have been applied to interpret data sets and to define the anomalies. As a first step, the frequency distribution of the data was examined through the frequency plots and EWMA control charts [24] of each element that can help to identify the type of distribution of the data and the outlier sites. To detect the relationships between the elements contents in moss and to determine the potentially influencing environmental factors partial component analysis (PCA) were used that explores the data onto hidden multivariate structures and 
explains their different means [25]. The most important PCs were determined and discussed. The statistical analyses were conducted using the MINITAB 17 software package.

\subsection{Results and discussion}

The frequency distribution of the data was examined through the frequency plots of each element. Current data represent different population or distributions indicating the data are affected by different emission process and are spatially dependent. The ${ }^{222} \mathrm{Rn}$ data of Terrace II follow normal distribution $(\mathrm{P}=0.245)$ by indicating stable values and distribution of ${ }^{222} \mathrm{Rn}$. The sorted ${ }^{222} \mathrm{Rn}$ data of Terrace I and Terrace follow exponential distribution (respectively $\mathrm{y}=0.635 \mathrm{e} 0.217 \mathrm{x} \mathrm{R} 2=0.969$ and $y=0.3279 e 0.2363 x, R 2=0.897$ ) followed high variation of the data. For a better interpretation of the results descriptive statistic is applied to the data matrix (Table 2).

Table 2 Data of descriptive statistic analysis of ${ }^{222} \mathrm{Rn}$ data matrix

\begin{tabular}{llll}
\hline Statistical Parameters & Terrace-II & Terrace-I & Terrace \\
\hline Mean $\left(\mathrm{kBqm}^{-3}\right)$ & 61.18 & 32.05 & 26.21 \\
Median $\left(\mathrm{kBqm}^{-3}\right)$ & 59.05 & 13.40 & 13.50 \\
Standard Deviation & 25.63 & 35.71 & 28.67 \\
CV\% & 42 & 111 & 109 \\
Kurtosis & 0.40 & -0.55 & -0.84 \\
Skewness & 0.73 & 0.94 & 0.75 \\
Minimum $\left(\mathrm{kBqm}^{-3}\right)$ & 22.37 & 0.90 & 0.90 \\
Maximum $\left(\mathrm{kBqm}^{-3}\right)$ & 130 & 105.9 & 84.9 \\
Count & 26 & 26 & 26 \\
\hline
\end{tabular}

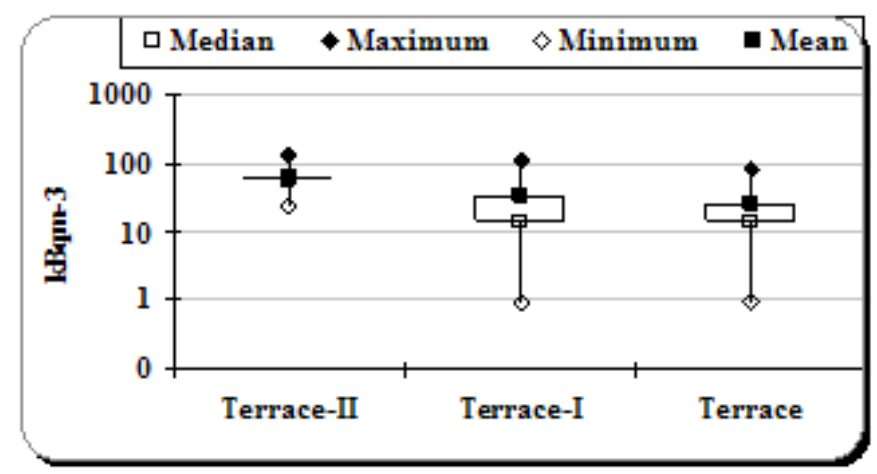

Fig. 4 Box plot diagram of Rn concentration data

The order of the median concentration of ${ }^{222} \mathrm{Rn}$ on each Terrace is ${ }^{222} \mathrm{Rn}_{\text {Terrace II }}>{ }^{222} \mathrm{Rn}_{\text {Terrace I }}>\cong{ }^{222} \mathrm{Rn}_{\text {Terrace }}$ as is shown in Fig. 4. High disparity exists on the Rn. concentrations data of Terrace I and Terrace that are characterized by high values of the coefficients of variation (CV\% $>75 \%$ ) (Table 2$)$, showing the influence of different factors. The distribution of ${ }^{222} \mathrm{Rn}$ data of each Terrace is shown on EWMA charts (Fig. 5, 6, 7).

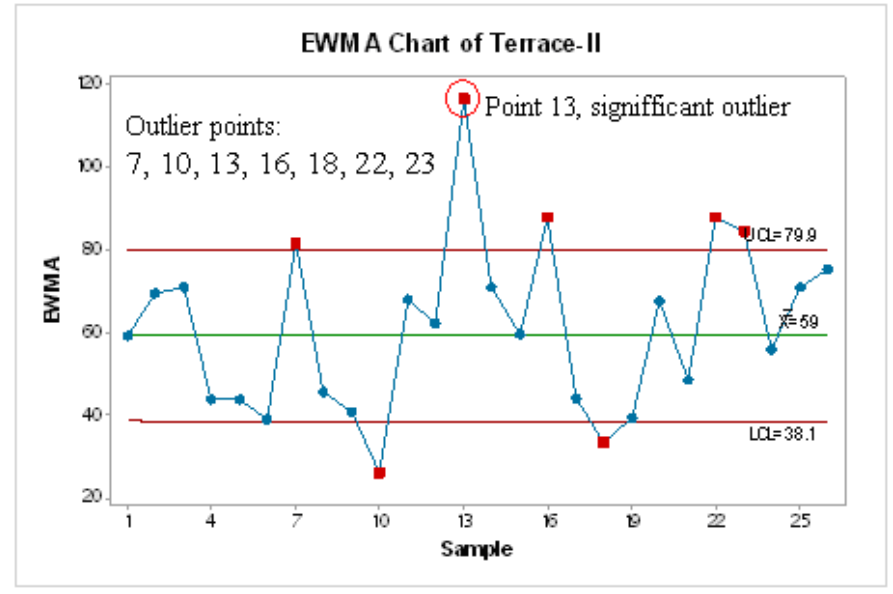

Fig. 5 Test Results for EWMA Chart of Tirana River terrace II

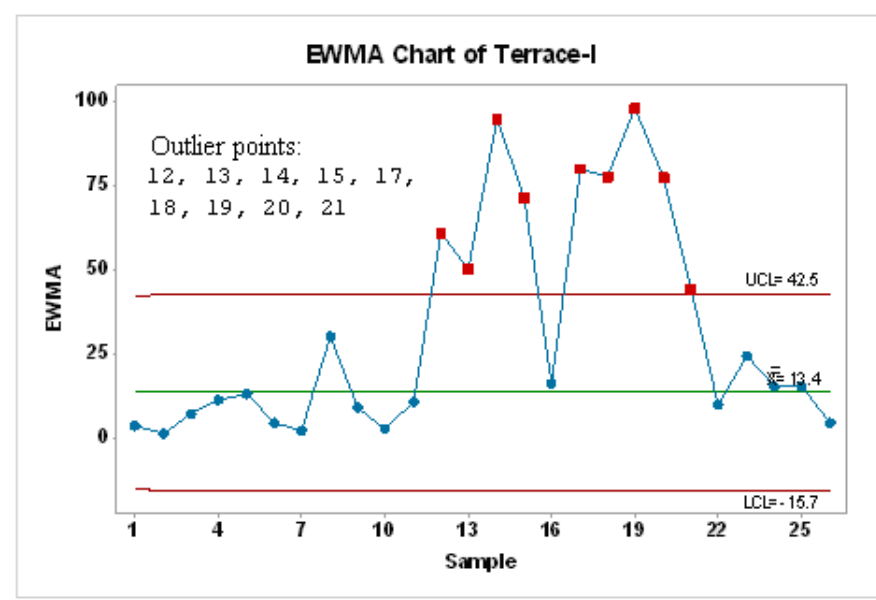

Fig. 6 Test Results for EWMA Chart of Tirana River terrace I

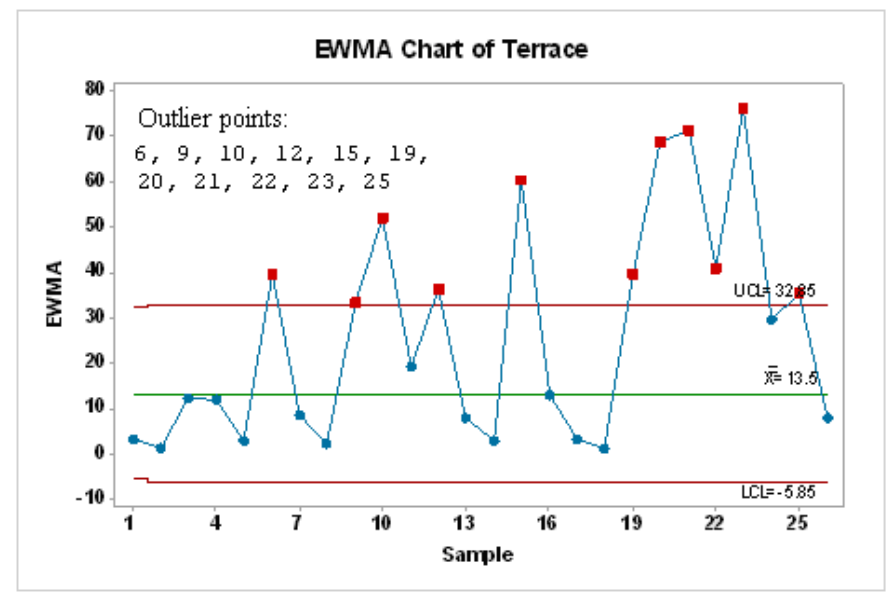

Fig. 7 Test Results for EWMA Chart of Lana River

The points more than 1.00 standard deviations from centre line are pointed as outliers (anomaly). The respective median values of each Terrace are selected as centre lines.

Almost the second terrace of Tirana River is formed up by a soil type-inorganic clays and sands with high gas radon level 
(22.37 to $130.0 \mathrm{kBqm}^{-3}$ ). The soils of the first terrace of Tirana River and the terrace of Lana River are characterized by lower concentration range of ${ }^{222} \mathrm{Rn}, 0.90$ to $105.9 \mathrm{kBqm}^{-3}$ and 0.90 to $84.9 \mathrm{kBqm}^{-3}$ respectively, compared with the second terrace of Tirana River. We think the concentration of ${ }^{222} \mathrm{Rn}$, higher than $30 \mathrm{kBqm}^{-3}$ found in the soils of these terraces came from the second terrace of Tirana River through the erosion process.

Similarity test is applied to ${ }^{222} \mathrm{Rn}$ data to examine the similarity of ${ }^{222} \mathrm{Rn}$ distribution between three Terraces by using ANOVA Single Factor which analyze the variances of each column (Terrace). The ANOVA results are shown in Table 3.

Table 3 The results of ANOVA Single Factor Analysis (Summary)

\begin{tabular}{lllll}
\hline Groups & Count & Sum & Average & Variance \\
\hline Terrace-II & 26 & 1591 & 61 & 657 \\
Terrace-I & 26 & 833 & 32 & 1276 \\
Terrace & 26 & 681 & 26 & 822 \\
\hline
\end{tabular}

\begin{tabular}{lllllll}
\multicolumn{7}{c}{ ANOVA } \\
\hline $\begin{array}{l}\text { Source of } \\
\text { Variation }\end{array}$ & SS & $d f$ & $M S$ & $F$ & P-value & F crit \\
\hline $\begin{array}{l}\text { Between Groups } \\
\text { Within Groups }\end{array}$ & 18249 & 2 & 9124 & 9.939 & 0.000148 & 3.119 \\
Total & 68852 & 75 & 918 & & & \\
\hline
\end{tabular}

The data of ANOVA analysis show that the data of each Terrace differ significantly from each other $(\mathrm{F}=9.939>$ Fcrit $=$ $3.119, \mathrm{P}<0.05)$ indicating different factors affect the disparity of ${ }^{222} \mathrm{Rn}$. content. Similarity level between ${ }^{222} \mathrm{Rn}$ distributions between Terraces under investigation is tested by cluster analysis (CA) that show moderate similarity ( $\cong 59 \%$ ) on the distribution of ${ }^{222} \mathrm{Rn}$ on Terrace I and Terrace, and very low similarity ( $\cong 43 \%$ ) of both of them with Terrace II.

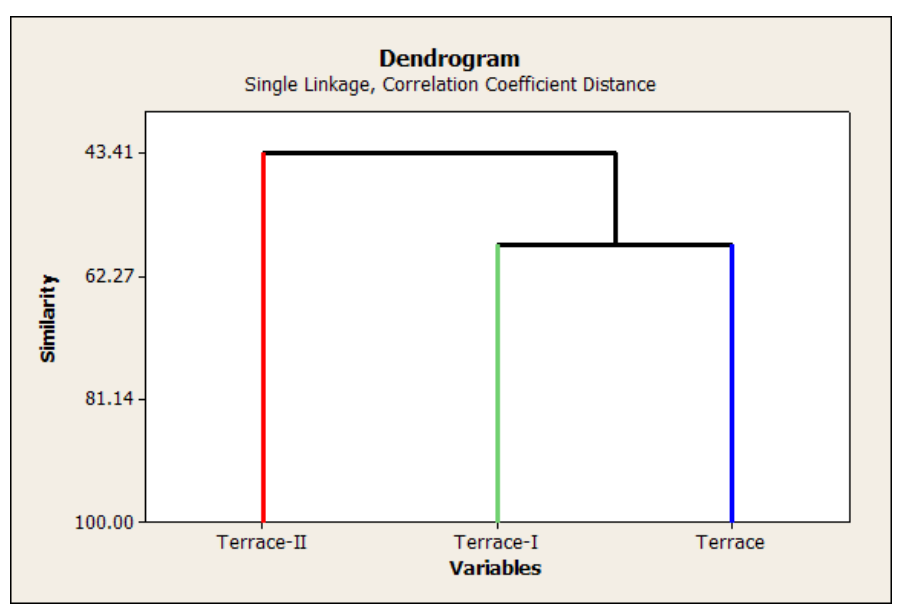

Fig. 8 The dendrogram of CA analysis of ${ }^{222} \mathrm{Rn}$ data matrix
For a better interpretation of results PCA analysis was used to the ${ }^{222} \mathrm{Rn}$ matrix data. Two main PCs (factors) were extracted that were interpreted as source categories contributing to ${ }^{222} \mathrm{Rn}$ content of each Terrace. The identification of the source categories was undertaken by examination of the profiles of the PCs, i.e, high loadings.

Table 4 Principal Component Analysis of ${ }^{222} \mathrm{Rn}$ data of Terrace-II, Terrace-I and Terrace

\begin{tabular}{llcc}
\hline \multicolumn{4}{c}{ Eigenanalysis of the Correlation Matrix } \\
\hline Eigenvalue & 1.280 & 0.873 & 0.847 \\
Proportion & 0.427 & 0.291 & 0.282 \\
Cumulative & 0.427 & 0.718 & 1.000 \\
Variable & PC1 & PC2 & \\
Terrace-II & -0.559 & -0.826 & \\
Terrace-I & 0.589 & -0.332 & \\
Terrace & 0.584 & -0.456 & \\
\hline
\end{tabular}

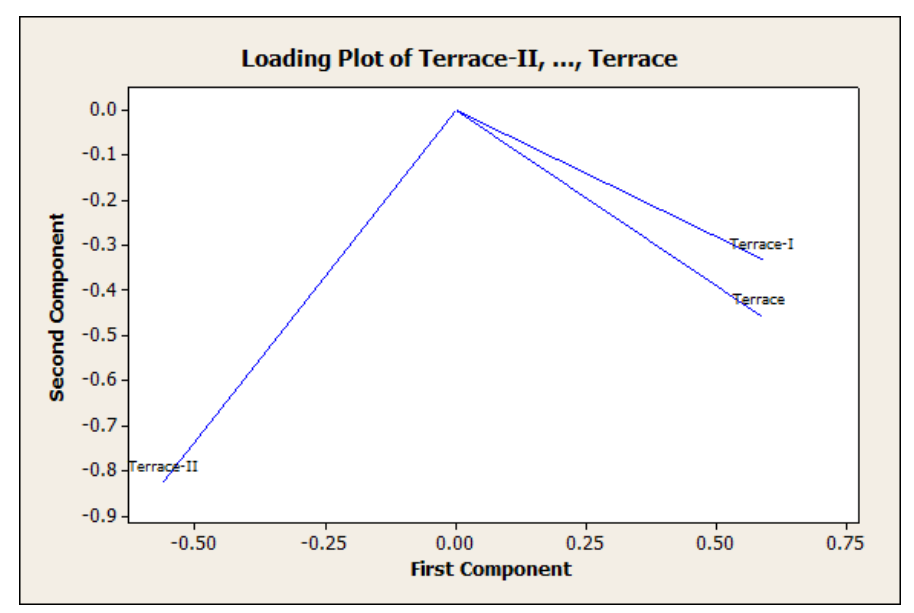

Fig. 9 The graph of loading plot of PC analysis onto ${ }^{222} \mathrm{Rn}$ data matrix

PC 1 is the strongest factor that represents $42.7 \%$ of the total variance and accounts high positive loads of ${ }^{222} \mathrm{Rn}$ variation data of Tirana Terrace I and Lana Terrace and high negative loads of Terrace II. The concentration in high levels $\left(>40.0 \mathrm{kBqm}^{-3}\right)$ of ${ }^{222} \mathrm{Rn}$, found in soils of the second terrace of Tirana River, we think that they have originated from "terra rosa", which extends throughout on Dajti Mountain slopes that is close to the studied area. In addition, another source of ${ }^{222} \mathrm{Rn}$ have been the ore deposits as the bauxite and radioactive coal outcrops, which are located near Tirana urban area (Dajti Mountain slopes).

PC2 is the next factor that represents $29.1 \%$ of the total variance and accounts high negative loads of ${ }^{222} \mathrm{Rn}$ variation data of all Terraces under investigation, with the highest influence to Terrace II. Based on the concentration level and geographic distribution of ${ }^{222} \mathrm{Rn}$, we have concluded that the soils that are the prone of radon gas in the first terrace of the Tirana River and the terrace of the Lana River have originated from the second terrace of the Tirana River by the erosion process. 


\section{Conclusions}

The following conclusion was deduced from the researches titled "The evaluation of radon concentration in the urban area foundation of Tirana Capital City, Albania" and "The engineering geological mapping in scale 1:10000":

- The level of the radon concentration in soil gas of Tirana urban area is interdependent to the soils type.

- In the second terrace of the Tirana River, the radon concentration in foundation soil gas ranges from 28.0$33.6 \mathrm{kBqm}^{-3}$ up to $994.7-130.0 \mathrm{kBqm}^{-3}$, 0.9-9.0 $\mathrm{kBqm}^{-3}$ to $79.32-105.9 \mathrm{kBqm}^{-3}$ and in the Lana River terrace it ranges from $0.90-12.0 \mathrm{kBqm}^{-3}$ to $48.7-84.9 \mathrm{kBqm}^{-3}$.

- Almost $94 \%$ of the foundation soils of the second terrace of the Tirana River are characterized by the high value of the radon concentration in soil gas.

- In the first terrace of the Tirana River is found that $30.0 \%$ of the foundation soils have the high value of the radon concentration in soil gas.

- In the terrace of the Lana River are distinguished about $43.0 \%$ of the foundation soils with high value of the radon concentration in soil gas.

- The radon potential in foundation soils of $54.0 \%, 14.0 \%$ and $32.0 \%$ of the Tirana urban area is respectively characterized by high, medium and low level of radon gas concentration in the foundation soils. It means that half of the Tirana urban area is built by foundation soils, which poses a high risk.

- For the mitigation and prevention of the dangers posed by exposure of the radon gas, it is necessary to know its geographical distribution and concentration level in soils and rocks foundation along dwelling area.

\section{Acknowledgments}

The authors would like to thank the reviewers for the really useful comments on the paper, who have contributed to increasing the quality of the present paper. We also thank the editor staff and chief Prof. Dr. Krisztina László of the journal, for the fruitful discussions.

\section{References}

[1] Choubey, V. M., Ramola, R. C. "Correlation between geology and radon levels in groundwater, soil and indoor air in Bhilangana Valley, Garhwal Himalaya, India." Environmental Geology. 32(4), pp 258-262. 1997. https://doi.org/10.1007/s002540050215

[2] Cohen, B. L. "Relationship between exposure to radon and various types of cancer." Health Physics. 65, pp. 529-531. 1993.

[3] Darby, S., Whitley, E., Howe, G., Hutchings, S. "Radon and cancers other than lung cancer in underground miners: a collaborative analysis of 11 studies." Journal of the National Cancer Institute. 87(5), pp. 378-384. 1995.
[4] Darby, S., Hill, D., Auvinen, A., Barros-Dios, J. M., Baysson, H., Bochicchio, F., Deo, H., Falk, R., Forastiere, F., Hakama, M., Heid, I., Kreienbrock, L., Kreuzer, M., LaGrarde, F., Makelainen, I., Muirhead, C., Oberaigner, W., Pershagen, G., Ruano-Ravina, A., Ruosteenoja, E., Rosaria, A.S., Tirmarche, M., Tomasek, L., Whitley, E., Wichmann, H. E., Doll, R. "Radon in homes and risk of lung cancer: collaborative analysis of individual data from 13 European case-control studies." British Medical Journal. 330, pp. 223-228. 2005.

https://doi.org/10.1136/bmj.38308.477650.63

[5] Darby, S., Hill, D., Deo, H., Auvinen, A., Barros-Dios, J. M., Baysson, H., Bochicchio, F., Falk, R., Farchi, S., Figueiras, A. "Residential radon and lung cancer - detailed results of a collaborative analysis of individual data on 7148 persons with lung cancer and 14208 persons without lung cancer from 13 epidemiologic studies in Europe Scand." Journal of Work, Environment \& Health. pp. 1-84. 2006.

https://doi.org/10.5271/sjweh.969

[6] Dogjani, S. "Study of Radon concentration measurements in the soils and indoors of Tirana city, Albania." Archive of Geological Survey of Albania. pp. 17-64. 2005.

[7] Dogjani, S., Reci, H. "Comparison of radon level concentration in soils with the natural radionuclides content in some regions of Ionain coastal area, in Albania." European Scientific Journal. 3, pp. 71-78. 2014.

[8] Gruber, V., Bossew, P., Tollefsen, T., De Cort, M. "A first version of a European Geogenic Radon Map (EGRM)." http://www. radon.eu/workshop2012/ pres/03 gruber_egrm_praesforwebpage.pdf

[9] Kemski, J., Siehl, A., Stegemann, R., Valdivia-Manchego, M. "Mapping the geogenic radon potential in Germany." Science of The Total Environment. 272(1-3), pp. 217-230. 2001.

https://doi.org/10.1016/S0048-9697(01)00696-9

[10] Krewski, D., Lubin, J. H., Zielinski, J. M., Alavanja, M., Catalan, V. S., Field, R. W., Klotz, J. B., Létourneau, E. G., Lynch, C. F., Lyon, J. L., Sandler, D. P., Schoenberg, J. B., Steck, D. J., Stolwijk, J. A., Weinberg, C., Wilcox, H. B. "A combined analysis of North American case-control studies of residential radon and lung cancer." Journal of Toxicology and Environmental Health, Part A. 69, pp. 533-597. 2006. https://doi.org10.1080/15287390500260945

[11] Lubin, J. H., Wang, Z. Y., Boice, J. D. "Risk of lung cancer and residential radon in China: pooled results of two studies." International Journal Cancer. pp. 109-132. 2004. https://doi.org/10.1002/ijc. 11683

[12] Matolin, M., Jane, Z., Neznal, M., Neznal., M. "Geometry of soil gas sampling, soil permeability and radon activity concentration." Radon Investigation in CR, Geological Survey (VIII). pp. 27-29, Prague. 2000.

[13] Muceku, Y., Lamaj, M. "Engineering geological mapping for urban development and regional planning in Tirana-Vora area." Bulletin of Albanian Geosciences, Tirana. 2, pp. 5-16. 2005.

[14] Muceku, Y. "The engineering geological mapping for urban development and planning of Tirana-Durresi-Kavaja region, scale 1:10000. Geological Survey of Albania. pp. 158-175. 2005.

[15] Muceku, Y. "Assessment of geomorphology conditions of Tirana-Vora area for urban planning and development." Bulletin of Albanian Geosciences, Tirana. 1, pp. 33-46. 2006.

[16] Muceku, Y., Lazo, P. "The chemical-mineralogical composition and their effect in physical and mechanical properties of cohesive soils in Tirana area, Albania." Fresenius Environmental Bulletin, Germany. 22(10a), pp. 306-315. 2013. 
[17] Neznal, M., Neznal, M., Šmarda, J. "Correlation between radon in soil gas and local geology - Some remarks, in Radon investigation in CS." Edited by I. Barnet, Czech Geological Survey, Prague. 3, pp. 24-28. 1992.

[18] Neznal, M., Neznal, M., Šmarda, J. "Reconnaissance Technique for Radon Risk Classification of Foundation Soils." In: Proceedings of the 8th International Congress of the International Radiation Protection Association, Montréal. 1, pp. 1359-1362. 1992.

[19] Neznal, M., Neznal, M., Šmarda, J. "Variability of Radon with Depth in Various Soil Profiles." In: Barnet, I., Neznal, M. (eds.) Radon investigations in Czechoslovakia. Vol. 5, pp. 55-61. Czech Geological Survey, Prague. 1994.

[20] Neznal, M., Neznal, M., Šmarda, J. "Evaluation of Soil Gas Radon Concentration Data-Some Remarks." In: Barnet, I., Neznal, M. (eds.) Radon investigations in Czechoslovakia. Vol. 5, pp. 37-41. Czech Geological Survey, Radon v.o.s., Prague. 1994.

[21] Neznal, M., Neznal, M., Šmarda, J. "Radon risk classification of foundation soils and other radon measurements by private firms." Bulletin Scientifique l'Association Ingénieurs Électriciens Sortis de l'Institut Montefiore. 3, pp. 31-34. 1995.

[22] Neznal, M., Neznal, M., Šmarda, J. "Assessment of radon potential of soils-A five-year experience." Environment International. 22(Supplement 1), pp. 819-828. 1996.

[23] Neznal, M., Neznal, M. "Measurements of Radon Exhalation Rate from the Ground Surface: Can the Parameter be used for a determination of radon potential of soils?" In: Barnet, I., Neznal, M., Mikšová, J. (eds.) Radon investigations in Czechoslovakia. Vol. 9, pp. 16-25. - Czech Geol. Survey, RADON v.o.s., Prague. 2002.

[24] Qarri, F., Lazo, P., Stafilov, T., Frontasyeva, M., Harmens, H, Bekteshi, L., Baceva, K., Goryainova, Z. "Multi-elements atmospheric deposition study in Albania." Environmental Science and Pollution Research. 21, pp. 2506-2518. 2013.

https://doi.org/10.1007/s11356-013-2091-1
[25] Reimann, C., Filzmoser, P., Garrett, R. G. "Factor analysis applied to regional geochemical data: Problems and possibilities." Applied Geochemistry. 17, pp. 185-206. 2002.

[26] Samtani, C. N., Nowatzki, E. A. "Unified Soil Classification System, (ASTM D 2487)." Soils and Foundations, National Highway Institute. Reference Manual, Vol. I, pp. 3-25. 2006

[27] Samet, J. M. "Radon and lung cancer." Journal of the National Cancer Institute. 81, pp. 745-757. 1989.

[28] Sundal, A. V., Henriksen, H., Soldal, O., Strand, T. "The influence of geological factors on indoor radon concentrations in Norway." Science of The Total Environment. 328(1-3), pp. 41-53. 2004.

https://doi.org/10.1016/j.scitotenv.2004.02.011

[29] Tollefsen, T., Cinelli, G., Bossew, P., Gruber, V., De Cort, M. "From the European indoor radon map towards an atlas of natural radiation." Radiation Protection Dosimetry. 162(1-2), pp. 129-134. 2014. https://doi.org/10.1093/rpd/ncu244

[30] Vaupotič, J., Žvab Rožič, P., Barišić, D. "Environmental aspect of radon potential in terra rossa and eutric cambisol in Slovenia." Environmental Earth Sciences. 66(1), pp. 223-229. 2012. https://doi.org/10.1007/s12665-011-1228-0

[31] Vaupotič, J., Barišić, D., Kobal, I., Lulić, S. "Radioactivity and Radon potential of the terra rossa soil." Radiation Measurements. 42(2), pp. 290-297. 2007.

https://doi.org/10.1016/j.radmeas.2007.01.034 